\title{
Acculturation of Knowledge through Sustainable Language Engineering for National Development: The Case of Igbo
}

\author{
Chinwe E. Obianika \\ Mercy Agha Onu
}

Ebonyi State University, Abakaliki, Nigeria

doi: 10.19044/esj.2016.v12n17p373 URL:http://dx.doi.org/10.19044/esj.2016.v12n17p373

\section{Abstract}

The aim of this study is to find out the possible ways of domesticating knowledge gained through western education by the Igbo through sustainable language development. It also aims to make the knowledge accessible in the Igbo language for empowerment at the grassroots and ultimately for societal and national development. The need for this work is born out of the observation that the Igbo, as well as other tribes in Nigeria are rich with internationally acclaimed learned personalities. These personalities have distinguished themselves in various fields of human endeavor. Also, these achievements are made in foreign languages. Subsequently, these achievements have led to an increase in the relevance of such languages to the relegation of the scholars' own mother tongues and invariably their own people. By using the descriptive and inferential methods, the paper presents some neologism processes which non linguists can apply in their various academic fields. Also, they can come up with terminologies in the Igbo language for presenting relevant academic materials for use in teaching and learning the Igbo language. The use of these terminologies could be formal or informal as the need arises. Thus, these processes include extra-language borrowing, loan translations, intra-language borrowing, and specialization of dialectal phonological variants. Previously, metalanguage development efforts by governments had bypassed these professionals. Also, they have focused on developing the terminologies through linguists and selected professionals alone. This has resulted to the terminologies not being accessible to the intended end users. Among other things, this paper suggests that the call for the acculturation of knowledge and the processes of embarking on it should be made public in all institutions of higher education. This is carried out in the Igbo culture area and later extended to the Igbo in diaspora. However, the co-ordination of the process of the formalization of the terminologies should be left in the hands of the 
Igbo Studies Association (ISA). This official regulating body ensures the maintenance of professional standards and uniformity of usage.

Keywords: Linguists, Knowledge, Language, Igbo, Education

\section{Introduction}

The development and sustenance of world languages became more popular following the publication of the UNESCO documentation of endangered languages. This is because many seemingly 'healthy' languages were classified as 'threatened' to one degree or the other. Thus, the Igbo language is one of such languages. According to the predictions of the UNESCO document, they opined that the Igbo language might undergo extinction in the next few decades. One of the reasons for the speculation on the decline of the language is the limited use of the language in official matters, governance, textbook writing, educational instruction, law making, and other formal settings. Therefore, this reason is based on the fact that English language which is used in these settings is superior to the Igbo language. Hence, Igbo suffers neglect in the eyes of its owners, and more so to the rest of Nigerians and foreigners. One of the major reasons for the nonuse of the Igbo language in formal settings has been attributed to the limitation on the vocabulary of the language. Some Igbo speakers who would want to use the language in writing in other fields of human endeavors especially in the sciences, architecture, aviation, and the likes find it difficult to do so. This is because of the limitations in finding the appropriate expressions in the Igbo language. Moreover, the fact that the advancement in these fields which have been rendered in other languages and the increase in the advancement and relevance of such languages has received much contribution from Igbo nationals, have made the Igbo situation more perturbing. This paper therefore sets out to present some coinage processes which academics from other fields of life could apply to form words and expressions. Hence, this would facilitate their effective use of their language in presenting the findings emanating from their research to the public. Also, this will domesticate such knowledge in their culture and increases its relevance.

\section{Objective of the Study}

The objective of this study is to examine some coinage processes that are available for use by academics in different fields to form words and expressions in their own languages. This is done for the purpose of presenting reports of researches in these languages to increase the relevance of these languages and invariably their people. Furthermore, 
recommendations for the appropriate regulation of the process for effective management were also proffered.

\section{Methodology}

The research data for this study was gathered through library research. In addition, the methods of analysis are the descriptive and inferential methods with the Standard Igbo as the language to be focused on.

\section{The Use of the Igbo Language in Formal Education}

Nwadike (2002) stated that formal education was introduced to the Igbo nation by British missionaries sometime before 1882. Their efforts to reduce the Igbo language to writing and to use it as a medium of instruction in schools fared relatively well in spite of the challenges they faced. This continued for some years, but was later neglected after the adoption of the education ordinances which were enacted from 1882 by the colonial British Government in her West African colonies. According to Awoniyi (1978), these ordinances were "aimed at controlling and directing the educational activities of the Christian missionaries in what is now Nigeria." Consequently, the ordinances specified the conditions to be met by these mission schools before they would qualify to access the provided grants-inaid to schools. The most unpalatable to the missionaries among the conditions was the one that stipulated that, "the subjects of teaching shall be reading and writing of English language.” In the words of Nwadike (2002), "In effect, this meant that the teaching of Igbo and other indigenous languages would not qualify any Voluntary Agency for the grants-in-aid.” Therefore, this development put the missionaries in a precarious situation to get the grant-in-aid. However, it abandons the teaching of the Igbo language which was vital in evangelizing the Igbo nation. Also, they had invested so much into its development, and have forgotten the grants-in-aid and grapple due to the lack of funds that was crippling their evangelizing efforts. In the protests that the missionaries presented to the Colonial Office, they argued that the Igbo language should be made the foundation and the ladder for English language teaching. By this, they were accused of misplaced patriotism. Subsequently, the documents were carefully drawn not to include any derogatory remarks about the African languages. According to Awoniyi, their real attitude towards the languages was revealed by the abusive and frivolous statement of Rev. Metcalfe Sunter. In 1884, the first Inspector of Schools for West African Colonies when he arrived in Lagos stated:

"I regard these said languages as only

interesting to comparative philologist and never likely to become of any practical use to civilization.” P. 65 
On another occasion, it was stated to have made an even more provocative statement:

"The native must and will know

English in spite of all well-meaning but diseased notions; it is the language of commerce and the only education worth a moment's consideration.” p 65

Thus, the bid to use the Igbo language in formal education had suffered many challenges even from its very inception. However, centuries after the colonial era, the Igbo still manifest some effects of the colonial mental manipulation and subjugation. This is evidenced by their seeming inaction against the situation of the language. As stated by Engholm (1965), they are not appreciative of the following:

"Language (mother tongue) is the key to the heart of a people. If we lose the key, we lose the people. If we treasure the key and keep it safe, it will unlock the door to untold riches, riches which cannot be guessed at from the other side of the door." P15

However, sequel to the 1882 education edict, an American based philanthropic body, the Phelps-Stokes Funds, were interested in American as well as Negro education. They intervened by setting up two commissions in 1920. Nwadike (2002) opined that the first report of that commission was released in 1922 and in part contained the following:

"Native tongue is immensely more vital in that it is one of the chief means of preserving whatever is good in Native Customs, ideas and ideals, and thereby preserving what is more important than all these, namely: Native self-respect..... All people have an inherent right to their language. It is the means of giving expression to their own personality, however primitive they may be .... No greater injustice can be committed against a people than to deprive them of their own language.” Lewis, (1962, p63)

After submission to the Colonial Office in London, the result of the commission generated a reaction that reverted its 1882 stance on the use of 
native languages in education in British Colonies. Consequently, the committee that was set up to create a memorandum to that effect was released in 1925. As quoted in Nwadike (2002), part of it read:

"This study of the educational use of the vernaculars is of primary importance. The committee suggests cooperation among scholars, with aids from governments and missionary societies, in the preparation of vernacular textbooks.... Textbooks prepared for use in English schools should be replaced where necessary by others better adapted, the foundations and illustrations being taken from African life and surroundings. Provision will need to be made for this by setting aside temporarily, men possessing the necessary qualifications." P60

In the assessment of Nwadike, this recommendation ultimately generated "one of the best colonial enactments which met with the yearnings of the people of Nigeria." One may then ask a pertinent question: if this enactment became operational in 1926, why are there no improvements in the fortunes of Nigerian languages particularly Igbo, 89 years after? Nigerian languages have remained the medium of instruction (in principle) in the first three years in primary schools. In practice though, many schools especially non-government owned schools pay only lip service to this policy if at all.

Currently, Igbo is studied at all levels of education as a course of study. Therefore, in many instances, the teachers still use English as a medium of instruction in teaching the Igbo language.

\section{The Need to Elaborate the Function of Nigerian Languages}

In the last section, we tried to underscore the problems which the Igbo language had to grapple with before it became operational as a medium of instruction in the first few years of primary education. It should be noted that the current national policy on education still upholds teaching of children with their mother tongue in their first three years of primary education. Therefore, this means that the Igbo language and indeed other Nigerian languages are not used as medium of instruction. This is used beyond the first three years in primary schools except when teaching the language in question. The situation thus portrays these languages to be inferior to the English language in the mind of the users. As a result, they 
treat it with levity. Consequently, it is significant importance to elaborate the function of the Igbo language. Thus, this will make it relevant in the daily communication in more areas of life. Part of the problems that teachers/scholars have in the use of Nigerian languages/Igbo in academics is the lack of adequate terminologies to use in doing so. This paper therefore undertakes to discuss some coinage processes which could be applied by scholars of any discipline to formulate terminologies. Therefore, these terminologies would enable them to communicate their research results and teach their disciplines in their mother tongues.

It is true that the formulation of new terminologies in different fields of life is not new in the advancement of Nigerian languages. Nevertheless, the difference here is that the individual scholars in different fields of life are given the tools they need to improve on their skills. Thus, this will assist them in formulating the needed terminologies for their own use. This is contrary to what was obtainable previously where professional language engineers alone were left with the task instead of making them the operators of the regulating body. Hence, this is for the purpose of uniformity of usage and the maintenance of professional standards.

\section{Some Coinage Processes for Lexical Enrichment of the Igbo Language}

In the words of Emenanjo (2005), "all languages respond to the many facets of culture contact by willingly or unwillingly expanding their lexical inventory to enable them cope with expressions of these new realities." Therefore, we outline some of these strategies to the following:

Borrowing: This is a process of obtaining words from one language to the other. Languages of the world use this process for enrichment as they come in contact with new cultures. One of the factors that have made English language the richest of the world's languages is its ability to borrow from all the cultures it comes in contact with. Subsequently, Igbo and indeed all Nigerian languages should emulate this. However, there are principles guiding the use of this process:

A) The words "borrowed" are usually adapted to the sound system and grammar of the language.

B) The borrowed scientific terms are consistent as much as possible with the type of information and language of origin.

C) The acceptability of all new words was first tested before they are fully adopted.

Intra-Language Borrowing: The multiplicity of dialects in languages could be an asset in language engineering as dialectal variations could be utilized in various ways (Emenanjo, 2005). These ways include: 
A) Specialization of Dialectal Variants: In Igbo, there are certain words which exist only in some dialects. Thus, it can be formally adopted into the Standard. Example:

Ezu - lake Agulu dialect

Ntubiriko diplomacy - Arochukwu dialect

Mbuze - erosion - Aguata dialect

B) Specialization of Dialectal Phonological Variants: Example are:

Iru - face -as prefix (nganiru) from Onicha dialect

Ihu - face - as face/front from Owere dialect

C) Use of dialectal Variants as Synonyms

Loan Blends: During this process, the borrowed words are not taken wholly, but they are synthesized to blend with cultural/language features of the borrowed language.

Calques: This involves the capturing of the 'essence' or 'concept' of the terminology from the source culture, giving it an interpretation in the new culture, and giving it a local colour and meaning. It is usually in form of slangs, colloquialisms, and sometimes euphemisms. The expressions could be words, phrases, associative constructions, agentive, and instrumental phrases or sentences. Examples:

Aru agu $\longrightarrow$ aruagu

Working reading/studying sandwich programme

Nuru lere

Hear see

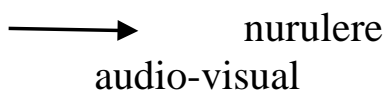

Elevation and Specialization of Slang and Colloquialisms: In using this technique, slang, words, phrases, and sentences which are clearly in non-standard forms are elevated and accorded respectability in the lexicon. Examples:

Ntuoyi $\longrightarrow$ air condition

A thing that causes cold

Obaramgbalielu $\longrightarrow$ high blood pressure

Blood that goes up

Awoko burning the midnight oil

Reading all through the night

Cherewere

express

Wait-and-take 
Aruagu

Working and reading

Specialization of Affixes: Igbo as a verb language utilizes a unidirectional word formation process where words are formed mainly from the verb base. Umeasiegbu (1986) and Anagbogu (1991) opines that the use of the homorganic nasal for marking instrumental nominals and the harmonizing open vowel prefix for marking agentive, is one of the many processes of nominalization employed for the enrichment in Igbo. In the following examples from Emenajo (1983), harmonizing prefixes are employed for deriving agentive and instrumental nominal. Examples:

Ogwu ala

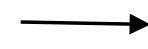

Ngwu ala

Omu mma

Mmu mma

Oso naazu

Nso naazu
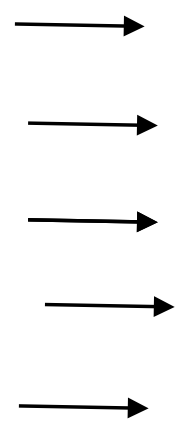

digger (+agentive)

digger (+instrumental)

sharpner (+agentive)

sharpner (+instrumental)

one who follow from behind

things which follows from behind

\section{Acculturation of Knowledge}

The essence of the foregoing is to equip scholars with necessary tools to enable them use their mother tongue in reporting the result of their academics research and creative output. Some of them include Philip Emeagwali - a super computer programmer, Prof Chinua Achebe - a winner of Noble prize for literature, Chimamanda Adichie - multiple international prize winner for literature etc. Academics and professionals who are of Nigeria/Igbo extraction have contributed to the advancement of their chosen disciplines and careers. However, they did so in foreign languages thereby enriching those languages and making them more relevant to the relegation of their mother tongue.

The use of Igbo/other Nigerian languages in publishing would make such knowledge available in those languages. Hence, this would make them the property of those cultures, thereby enriching them. Classical works like Chinua Achebe's 'Things Fall Apart' or Chimamanda Adichie's 'Purple Hibiscus' have in no small way enriched the English language. If such talents are directed even to a minimal extent towards the Igbo language 
which is their mother tongue, the language would have received a better boost than it is enjoying today.

At another instance, there are cultural knowledge and wisdom peculiar to every people. The expression of such knowledge is best accomplished through the use of their language. In the words of Lewis (1962), "all peoples have an inherent right to their language. It is the means of giving expression to their own personality, however primitive they may be.” Igbo language and indeed all Nigerian languages stand the risk of losing their wealth of native knowledge and civilization. This might occur if there is no formalized way of incorporating it into the modern technological advancement and application. The application of these processes of formulating terminologies serves the particular purpose of enabling the Nigerian academic to do so if they are willing. This thereby makes the knowledge native to the culture of those languages.

The use of these languages in serious academic and official matters to expand the sphere of the functionality of the language will give it and invariably the speakers, a better standing and prestige among the community of languages.

\section{Recommendations}

In this study, it is recommended that the 'Ohaneze Ndi Igbo' (the Pan Igbo solidarity organization) and many other languages and ethnic groups in Nigeria should have their corresponding organizations. Also, the Igbo Studies Association should liaise to make their nationals aware of the need to acculturate the knowledge available in their disciplines to be accessible in the Igbo language.

Seminars, workshops, and training programs should be organized at regular intervals for professionals of other disciplines who are of Igbo extraction on coinage processes for the elaboration of the Igbo metalanguage. Therefore, this would equip them with the necessary skills to formulate terminologies in the Igbo language suitable for use in their fields of endeavor and for the codification of their research outputs. The training materials should also be made available for use by others who might not be opportune to attend the programs.

\section{Conclusion}

In conclusion, the functionality of the Igbo/ Nigerian languages has not advanced much since the colonial era. The trend may continue unabated if academics and professionals of different works of life do not work in concert to equip themselves with and apply the necessary tools to create the needed terminologies. However, these terminologies would enable them acculturate the advancement made in their fields in Igbo/Nigerian languages. 


\section{References:}

Awoniyi, T.A. (1978). Yoruba Language in Education, 1846-1974. Ibadan: Oxford University Press.

Anagbogu, P. (1991). Nominalization in Igbo. Onitsha: Varsity Press Ltd.

Emenanjo, E. N. (1983). "Verb Derivational Morphology" in P. A. Nwachukwu (ed) Readings in the Igbo Verb. Onitsha: Africana-Feb, p. 43-59.

Emenanjo, E. N. (2005). "Beyond Okasusu Igbo: Igbo Metalanguage: Past, Present and Future" in Inno Nwadike and Clara Ikekeonwu (eds) Igbo Language Development: The Metalanguage Persspective. Enugu-Nigeria: CIDJP Press.p.5-23.

Engholm, E. (1965). Education Through English: The Use of English in African Schools. Cambridge:Cambridge University Press.

Lewis, L. J. (1962). Phelps-Stokes Report on Education in Africa. London: Oxford University Press.

Nwadike, I. U. (2002). Igbo Language in Education: An Historical Study. Obosi-Nigeria: Pacific Publishers.

Umeasiegbu, T. O. (1978). The Derivation of Agentive Nominalsin Igbo. M. Phil Thesis, University of Leeds. 